\title{
DUALIDADE E CONTRADIÇÕES NO PROJETO DE EDUCAÇÃO PROFISSIONAL BRASILEIRO
}

\section{DUALITY AND CONTRADITIONS IN THE BRAZILIAN VOCATIONAL EDUCATION PROJECT}

FARIAS, Rosane de Abreu $^{1}$

\begin{abstract}
RESUMO
O presente trabalho teve por objetivo discutir as contradições da formação profissional brasileira a partir da dualidade estrutural revelada pela relação capital-trabalho e seu reflexo na relação trabalho-educação. Buscou-se demonstrar a partir do estudos de Saviani (2003, 2007), Frigotto (2009) e Kuenzer (1997) como foi construída a dualidade educacional brasileira. Reconstituída a historicidade desse processo, utilizou-se de Rodrigues (1998), Ramos $(2011,2013)$ e Frigotto, Ciavatta e Ramos (2005) para ressaltar os sentidos de uma formação integrada a partir dos conceitos de Politecnia de Marx e Engels, e de escola Unitária de Gramsci. Assim, da confluência dos estudos de Rodrigues (1998) e Ramos (2013) foram configurados os quatros sentidos da integração da educação profissional ao ensino médio: o ético-político, o filosófico, o epistemológico e o pedagógico, como "travessia" para o ideal de politecnia.
\end{abstract}

PalaVRas-Chave: Formação Integrada; Dualidade educacional; Ensino médio integrado; Educação profissional

\section{ABSTRACT}

This paper aimed to discuss the contradictions of Brazilian vocational education from the structural duality revealed by the capital-labor relationship and its reflection on the workeducation relationship. We tried to demonstrate from the studies of Saviani $(2003,2007)$, Frigotto (2009) and Kuenzer (1997) how the Brazilian educational duality was built. Reconstituted the historicity of this process, we used Rodrigues (1998), Ramos (2011, 2013) and Frigotto, Ciavatta and Ramos (2005) to highlight the meanings of an integrated formation based on the concepts of Politecnia by Marx and Engels, and of Gramsci Unitary School. Thus, from the confluence of the studies by Rodrigues (1998) and Ramos (2013), the four meanings of the integration of vocational education into high school were configured: the ethical-political, the philosophical, the epistemological and the pedagogical, as "crossing" to the ideal of polytechnics.

KeYwORDS: Integrated formation; Educational duality; Integrated high school; Vocational education

${ }^{1}$ Doutoranda em Políticas Públicas e Formação Humana pela Universidade do Estado do Rio de Janeiro. Supervisora Educacional FAETEC/RJ. Rio de Janeiro, RJ Brasil. e-mail: ro.afarias@gmail.com 


\section{INTRODUÇÃO}

Como pensar a educação profissional no século XXI, sem retornarmos ao senso comum expresso pela relação intrínseca do "educar para o trabalho"? A expressão cunhada a partir da necessidade da classe mais pobre prover sua existência leva-nos a buscar nos primórdios da história a raiz dessa necessidade.

De acordo com Saviani, "o ato de agir sobre a natureza transformando-a em função das necessidades humanas é o que conhecemos com o nome de trabalho." (SAVIANI, 2007, p. 154). Logo, percebe-se que o trabalho é uma necessidade humana não apenas de prover economicamente a existência humana, mas sim de produzí-la.

Para o homem viver é necessário comer, vestir e abrigar-se²; logo, suas necessidades básicas de existência exigem que ele transforme a natureza para atendê-las, ou seja, interfira em seu ambiente, constituindo-se assim um processo dialético de produção e aprendizagem, um processo educativo. Ou, nas palavras de Saviani, "a produção da existência implica o desenvolvimento de formas e conteúdos cuja validade é estabelecida pela experiência, o que configura um verdadeiro processo de aprendizagem" (SAVIANI, 2007, p. 154). Assim, trabalho e educação são princípios ontológicos do homem por serem indissociáveis em sua natureza, e históricos por serem desenvolvidos ao longo do tempo de existência do próprio ser ${ }^{3}$.

Nessa perspectiva, considerando o homem um ser racional e capaz de pensar sobre a sua experiência vivida, o aperfeiçoamento de técnicas que melhorem sua produção de vida acontece de forma natural, da mesma maneira que, por ser um ser social, o compartilhamento e a socialização de suas formas de fazer são realizadas entre as diversas gerações que compõem seu grupo social. Ou, nas palavras de Gramsci, "na realidade, toda geração educa a nova geração, isto é, forma-a; a educação é uma luta contra os instintos ligados às funções biológicas elementares, uma luta contra a natureza, a fim de dominá-la e de criar o homem "atual" à sua época" (GRAMSCI, 1968, p. 142). Ou seja, não há diferenciações entre os homens além da geracional, todos são iguais e uns aprendem com os outros na produção da existência coletiva.

\footnotetext{
${ }^{2}$ Lei primeira descoberta por Marx, segundo expressa Engels em seu "Discurso diante do túmulo de Marx em 17 de março de 1883." Disponível em <https://www.marxists.org/portugues/marx/1883/03/22.htm> Acessado em 12/04/2016.

${ }^{3}$ Para uma maior exposição desta ideia, ver SAVIANI, D. Trabalho e educação: fundamentos ontológicos e históricos. Revista Brasileira de Educação, p. 152 - 165, 2007.
} 
DOI: $10.12957 /$ e-mosaicos.2019.46492

TRABALHO E DIVISÃo dO TRABALHO: PRINCÍPIO DA DUALIDADE EDUCACIONAL

De acordo com Frigotto (2009, p. 129),

(...) em toda história humana, os diferentes modos de produção (tribal, antigo, medieval, capitalista, socialista) sempre envolvem a tríade constituída por uma base material (econômico-social), por dimensões supra-estruturais vinculadas a valores ideologias, ideias, teorias, emoções e por instituições que consolidam, produzem e reproduzem as relações sociais.

Assim, a produção da existência humana, nos seus primórdios, de acordo com Saviani (2007), ocorria na forma de "comunismo primitivo", uma vez que não havia proprietários dos meios pelos quais esta se realizava. A terra, meio básico para a existência humana e para a satisfação de suas necessidades básicas, pertencia a todos; era uma propriedade coletiva daqueles que vivem nela e que dela necessitam para viver. Ou, como afirmam Frigotto, Ciavatta e Ramos (2006, p. 60):

Propriedade, no seu sentido ontológico, é o direito do ser humano, em relação e acordo solidário com outros seres humanos, de apropriar-se, transformar, criar e recriar pelo trabalho - mediado pelo conhecimento, ciência e tecnologia - a natureza para produzir e reproduzir a sua existência em todas as dimensões acima assinaladas.

Porém, como mostra Saviani (2007, p. 155), "a apropriação privada da terra, então principal meio de produção, gerou a divisão dos homens em classes". A partir de então, a sociedade foi dividida em classe dos proprietários e classe dos nãoproprietários. Isso levou à criação de valor de troca do trabalho, uma vez que para produzirem a própria existência, aqueles que não são proprietários produziriam ainda um excedente, ao mesmo tempo em que permitia aos proprietários viverem deste excedente, sem assim precisar produzir. Dessa forma, o trabalho transformou-se em mercadoria, deixando de ter um valor de uso para ter um valor de troca, e posteriormente ser elevado pela economia clássica à categoria de fundamento da riqueza das nações ${ }^{4}$.

No momento da divisão social em classes distintas, instala-se o fenômeno da dualidade que se tornou estruturante das relações sociais que foram estabelecidas de acordo com o modo de produção material em um espaço/tempo determinado.

\footnotetext{
${ }^{4}$ Adam Smith, em sua obra "A riqueza das nações", buscou no fundamento do trabalho a riqueza nacional.
} 
DOI: $10.12957 /$ e-mosaicos.2019.46492

Assim, o movimento histórico demonstra como essas relações foram se configurando, adaptando-se ou mesmo rompendo com as formas anteriores pelas quais a sociedade se organizava. Nesta perspectiva, Frigotto, Ciavatta e Ramos destacam que:

A história do trabalho transitou dos modos primitivos e tribais dos seres humanos se relacionarem com a natureza e os outros seres humanos para responderem às suas necessidades básicas, ao tripalium das sociedades escravocratas e servis até a atual forma de trabalho sob o capitalismo (FRIGOTTO; CIAVATTA; RAMOS, 2005, p. 61).

E os autores complementam que o trabalho:

(...) na sociedade capitalista caracteriza-se como trabalho assalariado. Vendendo a sua força de trabalho a outrem, 0 trabalhador recebe um valor por meio do qual ele pode satisfazer suas necessidades básicas. Nesta sociedade, a satisfação dessas necessidades tende a se reduzir à sua reprodução material (FRIGOTTO; CIAVATTA; RAMOS, 2005, p. 108).

Desta forma, a formação humana expressa pela relação trabalho-educação será também dividida em: trabalho para a classe não-proprietária e educação para a classe proprietária, como expressa Saviani (2007, p. 155):

[...] passaremos a ter duas modalidades distintas e separadas de educação: uma para a classe proprietária, identificada como a educação dos homens livres, e outra para a classe não proprietária, identificada como a educação dos escravos e serviçais. A primeira, centrada nas atividades intelectuais, na arte da palavra e nos exercícios físicos de caráter lúdico ou militar. E a segunda, assimilada ao próprio processo de trabalho.

O surgimento da escola, que se faz crer tenha sido pela necessidade de transmissão de conhecimentos de uma geração à outra, por meio da institucionalização do processo de aprendizagem, demonstra em sua gênese a supremacia de uma classe sobre a outra e a adaptação dos homens aos seus papéis sociais dentro de uma sociedade de classe. 
Assim, se nas sociedades primitivas, caracterizadas pelo modo coletivo de produção da existência humana, a educação consistia numa ação espontânea, não diferenciada das outras formas de ação desenvolvidas pelo homem, coincidindo inteiramente com o processo de trabalho que era comum a todos os membros da comunidade, com a divisão dos homens em classes a educação também resulta dividida; diferencia-se, em consequência, a educação destinada à classe dominante daquela a que tem acesso a classe dominada. E é aí que se localiza a origem da escola. A educação dos membros da classe que dispõe de ócio, de lazer, de tempo livre passa a organizarse na forma escolar, contrapondo-se à educação da maioria, que continua a coincidir com o processo de trabalho (SAVIANI, 2007, p. $155-156)^{5}$.

Tal divisão da educação expressava, segundo Gramsci, uma racionalidade da sociedade dividida em classes, "a divisão fundamental da escola em clássica e profissional era um esquema racional: a escola profissional destinava-se às classes instrumentais, ao passo que a clássica destinava-se às classes dominantes e aos intelectuais" (GRAMSCI, 1968, p. 118).

Frigotto corroborando, destaca:

Ela [a escola] nasce, no plano discursivo ideológico, como uma instituição pública, gratuita, universal e laica que tem, ao mesmo tempo, a função de desenvolver uma nova cultura, integrar as novas gerações no ideário da sociedade moderna e de socializar, de forma sistemática, o conhecimento científico. Todavia, a escola, na verdade, desde sua origem, foi organizada, sobretudo, para aqueles que não precisam vender sua força de trabalho e que têm tempo de viver a infância e adolescência fruindo o ócio (FRIGOTTO, 2009, p. 131).

Identificada assim a dualidade educacional como expressão da dualidade social sob o modo de produção capitalista, aumentou-se a necessidade de discursos e dispositivos legais que legitimassem essa dualidade; logo, como em outros aspectos da teoria liberal que constitui a base ideológica do modo de acumulação capitalista, a Teoria do Capital Humano serviu de recurso político-ideológico para a transformação da educação em fator econômico, ao mesmo tempo que transforma, sob a ideia de igualdade de condições, todos em proprietários, seja dos meios de produção ou da sua força de trabalho. Assim, "a naturalização de uma relação estruturalmente assimétrica entre capital e trabalho constitui o fundamento e a força

\footnotetext{
${ }^{5}$ Grifo do autor.
} 
ideológica de dissimulação da exploração" (FRIGOTTO, 2009, p. 130).

Desta forma, para Kuenzer (1997) a dualidade estrutural é a categoria de análise que permite compreender a tensão existente entre formação para a continuidade dos estudos e formação para o mercado de trabalho, existente no ensino médio brasileiro exatamente por seu caráter intermediário de formação. $\mathrm{Na}$ análise da autora sobre as legislações educacionais, a diferenciação de ofertas formativas para classes sociais distintas sempre esteve claramente exposta pelo princípio educativo tradicional ${ }^{6}$, no qual "a existência de dois projetos pedagógicos distintos que atendem às necessidades definidas pela divisão técnica e social do trabalho de formar trabalhadores instrumentais e trabalhadores intelectuais através de sistemas distintos" (KUENZER, 1997, p. 15).

Por outro lado, a referida autora ao historicizar o processo legislativo brasileiro no século passado destaca contradições virtuosas nos mesmos: na LDBN no 4.024/61, a equivalência dos cursos profissionais aos cursos secundários (clássico e científico) para fins de continuidade dos estudos; e na Lei no 5.692/71 a não incorporação da dualidade estrutural como "modelo de organização escolar", uma vez que a profissionalização foi compulsória demonstrou-se uma face democrática de uma escola igual para todos, ainda que apenas na forma da lei.

Porém, já no ano seguinte, conforme Kuenzer (1997), o Parecer no 45/72 ofereceu um leque de habilitações profissionais cujas base reduziram o núcleo comum dos currículos científicos e adicionaram, sem integrar, disciplinas da formação específica fragmentadas, sendo a integração deste currículo promovida nos estágios a serem realizados após o curso. A autora continua sua análise destacando que sob essa "inadequação conceitual e por falta de condições materiais" essa proposta nunca chegou a se concretizar.

Desta forma, o Parecer no 76/75, sob a justificativa de impossibilidades materiais, financeiras e humana de transformar todas as escolas em técnicas e justificando que o ensino é que deveria ser profissionalizante, legitimou a realidade tornando possível o retorno à dualidade. "Essa proposta, finalmente referenciada por uma lei, a no 7.044/82, acabou por se constituir em um novo arranjo conservador, reafirmando a escola como o espaço para os já incluídos nos benefícios da produção e do consumo de bens materiais e culturais" (KUENZER, 1997. p. 25).

Assim, Kuenzer destaca a correlação de forças entre progressistas e conservadores que existiu para a elaboração do projeto de educação para a Constituição Federal de 1988 e para elaboração da LDBN no 9.394/96. Em paralelo a discussão do Sistema Nacional de Educação que estava acontecendo, iniciou-se a

\footnotetext{
${ }^{6} \mathrm{~A}$ autora utiliza o conceito principio educativo tradicional a partir da formulação de Gramsci sobre a formação humanista clássica realizada pela burguesia para formação de seus intelectuais, cujas bases são o "domínio do conteúdos gerais, das ciências, das letras e das humanidades, considerados como únicos saberes socialmente reconhecidos como válidos para a formação daqueles que desenvolveriam as funções de dirigentes." (KUENZER, 1997, p. 14)
} 
DOI: $10.12957 /$ e-mosaicos.2019.46492

discussão do Sistema Nacional de Educação Tecnológica.

Esta proposta, inicialmente elaborada pela Secretaria Nacional de Ensino Técnico - SENETE, do MEC, com o apoio da Secretaria de Ciência e Tecnologia, insere-se no contexto mais amplo das políticas do Governo Collor, que prevêem necessidade de um aporte maciço de recursos para o desenvolvimento de novas tecnologias e para a formação de recursos humanos capazes de desenvolvê-las por intermédio de um sistema de ensino diferenciado, em paralelo, inclusive na gerência, ao Sistema Nacional de Educação (KUENZER, 1997, p. 40).

Ou seja, sob o discurso da necessidade de desenvolvimento científico e tecnológico nacional, a dualidade educacional retorna ao cenário político apesar de toda a discussão que vinha se realizando na elaboração da nova LDB com a participação da sociedade civil sobre um novo princípio educativo adequado a este processo de desenvolvimento da ciência e de sua aplicação tecnológica. Configurarse-ia como um sistema independente de formação com as seguintes formas de oferta: qualificação ocupacional, educação prática em nível de primeiro grau, formação técnica de nível médio, formação técnica de nível superior e formação profissional de nível superior. Percebe-se desta forma a espinha dorsal do viria ser posteriormente o Decreto Federal n 2.208/97 e o seu princípio educativo, que

prevê a formação tecnológica em diferentes níveis (hierárquicos), que deverá se intercomplementar para recompor a unidade das atividades, rompida pela divisão técnica do trabalho com sua decorrente hierarquização; o sistema prevê, portanto a formação profissional diferente e desigual, determinada pela função que cada "técnico" irá desempenhar na hierarquia do trabalhador coletivo; (...), estabelecendo-se, desta forma, a competência no fragmento como princípio pedagógico básico da educação tecnológica; (KUENZER, 1997, p. 46) ${ }^{7}$.

Segundo a autora, o princípio da escola dual retorna de forma mais elaborada e com um discurso mais afinado ao papel "democrático" da educação: todos tem acesso a educação e a uma formação de acordo com seus interesses individuais, 0 que o principio dissimula é o caráter hierárquico e meritocrático da formação, de acordo com o esforço individual pode-se ter mobilidade social porém no interior de seu ramo profissional; a dicotomia ciência-tecnologia (trabalho), uma vez que os cursos tecnológicos figurarão como oferta de formação para a aplicação da ciência,

\footnotetext{
${ }^{7}$ Grifos da autora.
} 
ou seja, serão cursos voltados para a execução e o saber prático, ao passo que as universidades serão os lugares de desenvolvimento científico, ou seja, para aqueles que produzem saber. Por fim, Kuenzer destaca o problema da dualidade no financiamento da educação, uma vez que o Sistema Nacional de Educação Tecnológica articularia parcerias com ministérios ligados as áreas profissionais para assim adquirir investimento público para suas ações.

\section{Pressupostos teóricos da FORMAÇÃo INTEGRADA}

Repensarmos o ensino médio enquanto etapa final da formação básica do sujeito é fundamental por ser nesta etapa de ensino que "a relação entre ciência e forças produtivas se manifesta; é uma etapa em que os sujeitos estão fazendo escolhas e, dentre essas escolhas também está a formação profissional, o projeto de vida subjetiva e social que se deseja e se pode perseguir" (RAMOS, 2013, p. 16). Ou, segundo Saviani (apud RODRIGUES, 1998, p.94), "no nível intermediário do sistema de ensino é que caberia o início dessa explicitação [o principio educativo do trabalho] e também do contato com a profissionalização, que só se daria plenamente a partir daí".

Ao discutir a construção do conceito de politecnia a partir dos autores Saviani, Frigotto, Kuenzer e Machado, destaca nas obras dos referidos autores, publicadas no período de 1984 a 1992, além de Rodrigues (1998), três dimensões da politecnia: a infraestrutural, a utópica e a pedagógica.

Por dimensão infraestrutural entender-se-ia as mediações do mundo do trabalho: os aspectos técnicos e tecnológicos, as mudanças científicas que influenciam no processo de trabalho e a qualificação profissional. O autor destaca que a incorporação do desenvolvimento científico ao processo de produção sob o capitalismo modificaria a relação do trabalhador com o conhecimento de seu trabalho, provocando uma "desqualificação progressiva do trabalho". Nesta perspectiva, defende que a base infraestrutural da politecnia encontra-se em "trabalhar teoricamente a contradição inerente aos modernos processos de trabalho com o fito de se identificar - dialeticamente - a virtualidade no interior da negatividade" (RODRIGUES, 1998, p. 62). Ou seja, reconhecer a importância da incorporação do desenvolvimento científico e tecnológico aos processos de trabalho e à formação do trabalhador.

$\mathrm{Na}$ atualidade, a dimensão infraestrutural da formação do trabalhador ganha maior destaque tendo em vista a constatação das mudanças do perfil profissional necessário ao processo de produção capitalista, denominado flexível pela crescente incorporação de bases científicas e tecnológicas (HARVEY, 1992). Assim, o perfil profissional necessário é do trabalhador apto a solucionar problemas na rapidez e flexibilidade do processo de produção imediatamente em curso, que tenha 
características pessoais para o trabalho em equipe, porém como um dos integrantes necessários que trabalha individualmente, e com certa base de conhecimentos científicos para o desempenho de suas funções técnicas e de relacionamento interpessoal. Desta forma, torna-se necessário ao modo de produção capitalista um profissional polivalente ${ }^{8}$. Na perspectiva de Saviani (2003) este é o elemento chave para a superação da dualidade educacional, uma vez que o próprio processo produtivo capitalista necessita de trabalhadores que dominem conhecimentos científicos além dos específicos, promove a universalização da escola que desta forma pode se constituir em uma escola unitária "que desenvolva ao máximo as potencialidades dos indivíduos (formação omnilateral) conduzindo-os ao desabrochar pleno de suas faculdades espirituais-intelectuais," e que assim deixaria "o terreno da utopia e da mera aspiração ideológica, moral ou romântica para se converter numa exigência posta pelo próprio desenvolvimento do processo produtivo" (SAVIANI, 2003).

A lógica da polivalência reitera a dualidade do sistema educacional e é a que subjaz à concepção pedagógica da Pedagogia das Competências (RAMOS, 2011), pois, ainda que se busque uma formação voltada para conhecimentos científicos e tecnológicos, mantêm-se para a classe trabalhadora uma formação restrita aos conhecimentos que a permitam inserir-se neste novo paradigma do mundo do trabalho, adaptado às tarefas a serem desempenhadas, porém de forma alienada de seu princípio criativo. A concepção de politecnia, ao contrário, destaca Rodrigues (1998), seria a possibilidade de superação dialética dessa polivalência, com conhecimentos "que apontem para uma reapropriação do domínio do trabalho" (RODRIGUES, 1998, p. 71).

Por dimensão utópica, Rodrigues (1998) destaca a compreensão dos aspectos filosóficos da concepção de sociedade vislumbrada pela politecnia, uma sociedade ideal, porém não idealizada. Ou seja, a dimensão utópica constituir-se-ia em um projeto de sociedade sem divisão de classes ou exploração de uns pelos outros. Este seria o ideal a ser alcançado por meio de possibilidades reais de mundanças na forma de organização econômico-social; um mundo possível, em oposição a uma concepção de sociedade idealizada, inacessível ou apenas possível no mundo das ideias ou da moral.

Assim, para o autor, a dimensão utópica da politecnia constitui-se no

\footnotetext{
${ }^{8}$ Rodrigues (1998), destaca que a polivalência do trabalhador tornou-se uma das necessidades do capital a partir das mudanças tecnológicas advindas da incorporação da ciência ao processo produtivo e consequentemente da automatização do mesmo, o que requer um trabalhador flexivel e adaptável a um leque de atividades profissionais diversificadas. Esta seria uma virtuosidade do processo de inovação tecnológica, uma vez que promoveria uma nova qualificação do trabalhador com bases mais amplas de conhecimento, o que se viabilizaria uma perspectiva politécnica de formação humana omnilateral, porém sob a lógica de acumulação capitalista, a formação organiza-se apenas em conhecimentos básicos e superficiais que possibilitem a adaptação a atividades profissionais simples e diversificadas, sem a necessidade de conhecimentos sobre seus fundamentos científicos.
} 
elemento de mediação das duas outras dimensões, uma vez que é ela o fundamento, o princípio necessário à elaboração de um projeto de sociedade que, para se realizar necessita de mudanças em seu projeto de formação humana que desenvolva a compreensão do processo produtivo e de suas contradições, possibilitando a atuação consciente do sujeito. Ou seja, "a politecnia representa uma ruptura, a partir da continuidade, no projeto qualificacional e, fundamentalmente, no projeto de formação humana posto pela sociedade burguesa." (RODRIGUES, 1998, p. 74) Ao mesmo tempo que se coloca como possibilidade de superação dialética da escola que se tem para uma escola futura.

Por dimensão pedagógica, entender-se-iam as mediações entre a realidade econômico-social e o projeto de sociedade desejado, na qual a escola não é a responsável por mudanças, mas uma das possibilidades de formação de consciência crítica que instrumentalize as mudanças. Para Rodrigues (1998), esta dimensão constitui-se no desafio a ser enfrentado, uma vez que ela seria a forma de ação escolar da politecnia, ou em suas palavras, "a dimensão pedagógica busca revelar os caminhos pelos quais a concepção de educação politécnica busca sua organicidade no interior da prática educacional escolar" (RODRIGUES, 1998, p. 83). Logo, percebe-se o desafio de construir um processo de formação progressista a partir da escola tradicional existente, com sua organização positivista, fragmentada e utilitarista, na qual o ideal de formação é científica, mas a realidade brasileira que se coloca é de uma escola pública precarizada para a classe trabalhadora.

Desta forma, o desafio pedagógico da politecnia para Rodrigues (1998) é não reduzir-se à simples formação polivalente que as mudanças tecnológicas no mundo produtivo requerem, nem a uma formação geral distante do mundo do trabalho ou sem ligação com ele. Ao contrário, "a politecnia se propõe a ultrapassar tanto a profissionalização estreita quanto a educação geral baseada nas áreas que tradicionalmente compõem o saber escolar" (RODRIGUES, 1998, p. 91).

Assim, Rodrigues destaca que as três dimensões da concepção de politecnia presentes nas obras que inauguram a discussão no Brasil relacionam-se na busca de mundanças da função da escola para sociedade atual, e que esta função seria mais significativa e produtiva quando enfatizada no ensino médio, uma vez que este, por sua característica intermediária de formação humana, permitiria compreensão da totalidade social em suas múltiplas manifestações. "O que se pretende é partir do fenômeno do trabalho moderno (dimensão infraestrutural) para a reestruturação das práticas pedagógicas (dimensão pedagógica), mediada por uma perspectiva mais ampla de transformação global da sociedade (dimensão utópica)." (RODRIGUES, 1998, p. 92).

Com base na obra de Gramsci (1968), na discussão realizada na década de 1980 para elaboração da LDBN, e a concepção de politecnia sintetizada pela obra de Rodrigues (1998), pode-se perceber como a concepção de educação profissional integrada ao ensino médio constitui-se na mediação destas com a realidade 
DOI: $10.12957 /$ e-mosaicos.2019.46492

econômica, social e histórica da sociedade brasileira. Desta forma, Ramos (2013, p. 2) destaca como

pilares conceptuais de uma educação integrada: um tipo de escola que não seja dual, ao contrário, seja unitária, garantindo à todos o direito ao conhecimento; e uma educação politécnica, que possibilita o acesso à cultura, a ciência, ao trabalho, por meio de uma educação básica e profissional.

A concepção de formação integrada, segundo Ramos (2013, p.2), é composta por três sentidos complementares: "como concepção de formação humana; como forma de relacionar ensino médio e educação profissional; e como relação entre parte e totalidade na proposta curricular.". Percebe-se, assim, uma perfeita articulação com as dimensões destacadas por Rodrigues (1998), ampliando-as em determinadas momentos.

Como principio filosófico da integração, a autora destaca a formação omnilateral com base na integração das

dimensões fundamentais da vida que estruturam a prática social. Essas dimensões são o trabalho, a ciência e a cultura. O trabalho compreendido como realização humana inerente ao ser (sentido ontológico) e como prática econômica (sentido histórico associado ao respectivo modo de produção); a ciência compreendida como os conhecimentos produzidos pela humanidade que possibilita 0 contraditório avanço produtivo; e a cultura, que corresponde aos valores éticos e estéticos que orientam as normas de conduta de uma sociedade (RAMOS, 2013, p. 3).

O princípio educativo do trabalho caracteriza-se como formação humana, uma vez que é pelo trabalho que o homem realiza-se enquanto homem produzindo sua existência, relaciona-se com outros homens produzindo cultura, e de tais relações produz, consequentemente, conhecimentos. Este seria o sentido ontológico do trabalho. Em seu sentido histórico, pode-se identificar a forma como o trabalho é organizado e realizado enquanto relações econômicas em determinado espaçotempo. Entende-se, assim, que o trabalho enquanto princípio educativo não tem a função de profissionalização, ou não significa formação polivalente para o mercado. Esses são sentidos dados pelo modo de produção capitalista com a finalidade de esvaziar o sentido emancipatório da formação humana; ou seja, em lugar da formação para a liberdade, coloca-se uma formação para a empregabilidade.

O segundo sentido da educação integrada, para Ramos (2013), é o da 
indissociabilidade entre educação profissional e educação básica, tomada então como um compromisso ético-politico com a classe trabalhadora. Um compromisso ético, uma vez que se reconhece que dada a realidade social brasileira, na qual os jovens da classe trabalhadora tem a necessidade de inserir-se no mercado de trabalho precocemente para prover suas necessidades, a integração constitui-se em proposta de formação unitária que permita ao jovem tanto essa inserção com consciência crítica da estrutura social da qual faz parte, quanto possibilidade de continuação de estudos. Ou, nas palavras da autora, "uma formação profissional que possibilite aos sujeitos jovens e adultos se apropriarem de conhecimentos que estruture sua inserção na vida produtiva dignamente" (RAMOS, 2013, p. 10). Um compromisso político, uma vez que dada a constatação desta realidade, propõe-se a ser possibilidade de superação da mesma, e não reprodutora da divisão de classes. Assim, a autora destaca como diretrizes ético-políticas: "integração de conhecimentos gerais e específicos; construção do conhecimento pela mediação do trabalho, da ciência e da cultura; utopia de superar a dominação dos trabalhadores e construir a emancipação - formação de dirigentes" (RAMOS, 2013, p. 9).

De acordo com Ramos (2013), o terceiro sentido seria a integração de conhecimentos gerais e específicos como totalidade. Este estaria mais relacionado ao currículo e à prática pedagógica escolar. Ao se pensar uma educação unitária, tornase necessário refletir sobre o caráter fragmentário da formação escolar que se consagrou como hegemônica e dual, na qual há disciplinas de formação geral e especifica, de saber acadêmico e profissional, de formação intelectual e manual, que expressa, no plano educativo, a dualidade de classes sob o modo de produção capitalista. O desenvolvimento tecnológico vem demonstrar que a produção de conhecimentos é um processo dialético entre teoria e prática, que se produz a partir da capacidade do homem de pré-idealizar aquilo que deseja realizar, experimentar seus projetos, constatar seu funcionamento, e assim produzir sínteses deste processo, que se tornam ciência. Ou seja,

é o processo tecnológico que possibilita o salto científico, nos levando a rever a ideia de que os conhecimentos gerais sejam teorias e que os conhecimentos específicos sejam a aplicação dessas teorias. Não existe essa separação que o positivismo nos fez crer ao longo da história, com base na qual se naturaliza a ideia de que o professor da educação básica ministra as teorias gerais, enquanto o professor da formação técnica ministra as suas aplicações (RAMOS, 2013, p. 13).

Nesta perspectiva, a proposta de integração da educação profissional ao ensino médio incorpora tanto a compreensão global do conhecimento quanto as múltiplas relações entre áreas de conhecimento, superando estes dois aspectos ao relacioná-los com a realidade social, possibilitando assim a compreensão da "realidade para além de sua aparência fenomênica" (RAMOS, 2013, p. 16). Logo, "os 
conteúdos de ensino são conceitos e teorias que constituem sínteses da apropriação histórica da realidade material e social pelo homem" (RAMOS, 2013, p. 16).

Desta forma, para a organização curricular, a autora elenca três pressupostos filosóficos necessários: a concepção de homem como ser histórico-social; a realidade concreta é uma totalidade, síntese de múltiplas relações; "compreender o conhecimento como uma produção do pensamento pela qual se apreende e se representam as relações que constituem e estruturam a realidade objetiva." (RAMOS, 2013, p. 17) Percebe-se assim, que a concepção de integração distingue-se de uma justaposição entre ensino médio e educação profissional, ou a polarização entre uma e outra, o que possibilita é um processo de reflexão sobre a prática desenvolvida de forma fragmentária a fim de construir-se uma prática que possibilite a compreensão do conhecimento em sua totalidade, em seu processo dialético de teoria e pratica.

Por esse caminho perceber-se-á que conhecimentos gerais e conhecimentos profissionais somente se distinguem metodologicamente e em suas finalidades situadas historicamente; porém, epistemologicamente, esses conhecimentos formam uma unidade (RAMOS, 2013, p. 18).

\section{CONSIDERAÇõES FINAIS}

Da exposição feita, pode-se perceber a confluência dos dois autores: as dimensões da politecnia destacadas por Rodrigues (1998) materializam-se nos sentidos da integração discutidos por Ramos (2013). A compreensão da dimensão utópica como os princípios filosóficos de um projeto de sociedade possibilita apreender na realidade brasileira a necessidade de uma formação que articule trabalho, ciência e cultura enquanto projeto de emancipação da classe trabalhadora, potencializando a formação humana com o trabalho enquanto princípio educativo, uma vez que promove a compreensão do processo produtivo e a inserção do trabalhador no mesmo de forma consciente e crítica. Assim, demonstra-se a necessidade de uma concepção de educação na perspectiva de resgatar o sentido sócio-humano do trabalho como elemento socializador da humanidade em oposição ao sentido socioeconômico restrito de atividade-mercadoria, mais que apenas aprender/ensinar os conhecimentos que são úteis à vida ou necessários ao mercado de trabalho, aprender os fundamentos do conhecimento produzidos historicamente pela humanidade que possibilite uma formação de dirigentes nas palavras de Gramsci (1968).

Nesse sentido, destaca-se a dimensão infraestrutural que nas palavras de Rodrigues (1998) seriam as mediações do mundo do trabalho, e que Ramos (2013) materializa como a indissociabilidade entre trabalho manual/intelectual, ou seja, sob a revolução científica e tecnológica das últimas décadas e a reestruturação produtiva, 
coloca para o capital a necessidade de trabalhadores que compreendam o processo produtivo e assim possam atuar no mesmo de forma flexível, permite atuar nesta contradição sob a perspectiva gramsciniana de que todo trabalho é composto por uma parte intelectual e outra manual, "(...) em qualquer trabalho físico, mesmo no mais mecânico e degradado, existe um mínimo de qualificação técnica, isto é, um mínimo de atividade intelectual criadora". (GRAMSCI, 1968, p. 07) Desta forma, a finalidade do conhecimento configura-se em formação humana que proporcione a compreensão do processo dialético de produção do mesmo, ou seja, que permita compreender a totalidade do conhecimento em relação a sua composição nas diversas especificidades de áreas.

Nenhum conhecimento é em si somente de ordem geral ou especifico, teórico ou prático, e sim conhecimentos que se relacionam em todo e partes que o compõem permitindo sua compreensão enquanto totalidade. Esta relação configurase no desafio da dimensão pedagógica destacada por Rodrigues (1998) e reafirmado por Ramos (2013) na proposta curricular a ser elaborada para a educação profissional integrada ao ensino médio. Reconhecer e organizar o currículo de forma integrada demonstra ser o principal desafio a ser enfrentado pela proposta, uma vez que práticas pedagógicas integradas requerem uma atitude docente, que com base nas dimensões apontadas anteriormente, compreenda a importância dessa integração para a sociedade e descubra formas de realizá-las. Ao mesmo tempo, não se pode isolar este desafio a atitude docente, uma vez que para que ela aconteça também são necessárias a mobilização das demais esferas que compõem o processo educativo, tais como: a comunidade escolar, a infraestrutura física e pedagógica necessária, o financiamento, etc.

Por fim, o sentido ético-político da educação profissional integrada ao ensino médio destacado por Ramos (2013), apesar de não ser definido claramente como uma dimensão para Rodrigues (1998) subjaz toda sua análise sobre politecnia no Brasil e a importância de sua definição como concepção para o ensino de $2^{\circ}$ grau (atual ensino médio) enquanto etapa intermediária de formação, principalmente para classe trabalhadora. Este sentido configura-se como a base de compreensão e definição das três dimensões anteriormente comentadas, uma vez que por ele entende-se a dualidade estrutural da realidade brasileira e a partir disso afirmar-se um compromisso com sua manutenção ou superação.

\section{REFERÊNCIAS}

FRIGOTTO, Gaudêncio; CIAVATTA, Maria; RAMOS, Marise. Ensino médio integrado: concepções e contradições. São Paulo: Cortez, 2005.

FRIGOTTO, Gaudêncio. Escola e trabalho numa perspectiva histórica: contradições e 
DOI: $10.12957 /$ e-mosaicos.2019.46492

controvérias. Sisifo. Revista de Ciências da Educação. Lisboa: [s.n.]. 2009. p. 129136.

GRAMSCI, Antonio. Os intelectuais e a organização da cultura. Rio de Janeiro: Civilização Brasileira, 1968.

HARVEY, David. A condição pós-moderna. São Paulo: Loyola, 1992.

KUENZER, Acácia Zeneida. Ensino médio e profissional: as políticas do Estado neoliberal. São Paulo: Cortez, 1997.

RAMOS, Marise. Concepção do Ensino Médio Integrado. Disponível em:

<http://www.iiep.org.br/curriculo_integrado.pdf> Acessado em 29/06/2013.

Cortez, 2011 a.

A pedagogia das competências: autonomia ou adaptação? 4. ed. São Paulo:

RODRIGUES, José. A educação politécnica no Brasil. Niterói: EdUFF, 1998.

SAVIANI, Dermeval. Trabalho e educação: fundamentos ontológicos e históricos. Revista Brasileira de Educação. 2007, p. 152 - 165.

O trabalho como principio educativo frente às novas tecnologias. In: FERRETTI, Celso João. Novas tecnologias, trabalho e educação: um debate multidisciplinar. 9. ed. Petrópolis: Vozes, 2003. p. 151-168.

Recebido em 05 de novembro de 2019

Aceito em 04 de dezembro de 2019

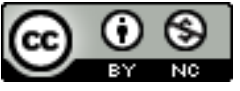

A e-Mosaicos Revista Multidisciplinar de Ensino, Pesquisa, Extensão e Cultura do Instituto de Aplicação Fernando Rodrigues da Silveira (CAp-UERJ) está licenciada com uma Licença Creative Commons - Atribuição-NãoComercial 4.0 Internacional.

Os direitos autorais de todos os trabalhos publicados na revista pertencem ao(s) seu(s) autor(es) e coautor(es), com o direito de primeira publicação cedido à e-Mosaicos.

Os artigos publicados são de acesso público, de uso gratuito, com atribuição de autoria obrigatória, para aplicações de finalidade educacional e não-comercial, de acordo com o modelo de licenciamento Creative Commons adotado pela revista. 